\title{
Führungswechsel bei ViscoTec
}

$B^{e}$ reits seit dem 1. Januar 2013 ist Martin Stadler neuer technischer Geschäftsführer bei der ViscoTec Pumpen- u. Dosiertechnik GmbH in Töging. Er folgt Vinzenz Gantenhammer, der seit der Gründung von ViscoTec im Jahre 1997 diese Position innehatte und in den Ruhestand verabschiedet wurde.

Georg Senftl wird weiterhin den kaufmännischen Bereich verantworten.

Stadler (45) ist Maschinenbau-Ingenieur und bringt als bisheriger Leiter des Geschäftsfeldes Kleben und Chemie eine mehr als 10-jährige Erfahrung in der Konstruktion, Entwicklung und im Vertrieb von Dosieranlagen und Dosierkomponenten mit.

ViscoTec hat weltweit knapp 100 Mitarbeiter und fertigt in Töging Do-

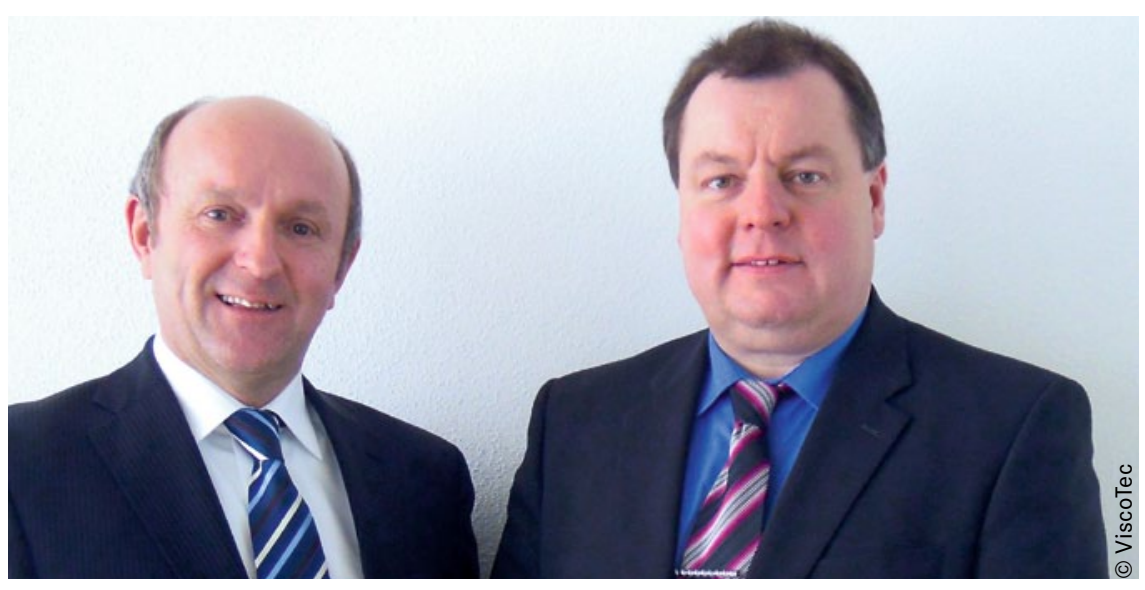

Georg Senftl (links) neben dem neuen technischen Geschäftsführer Martin Stadler.

sieranlagen sowie Komponenten, die z.B. zum Auftragen von Klebstoffraupen in vollautomatischen Montageprozessen verwendet werden. Ein- gesetzt werden die Anlagen in allen möglichen Industriebereichen von der Flugzeugindustrie bis hin zur Mikroelektronik.
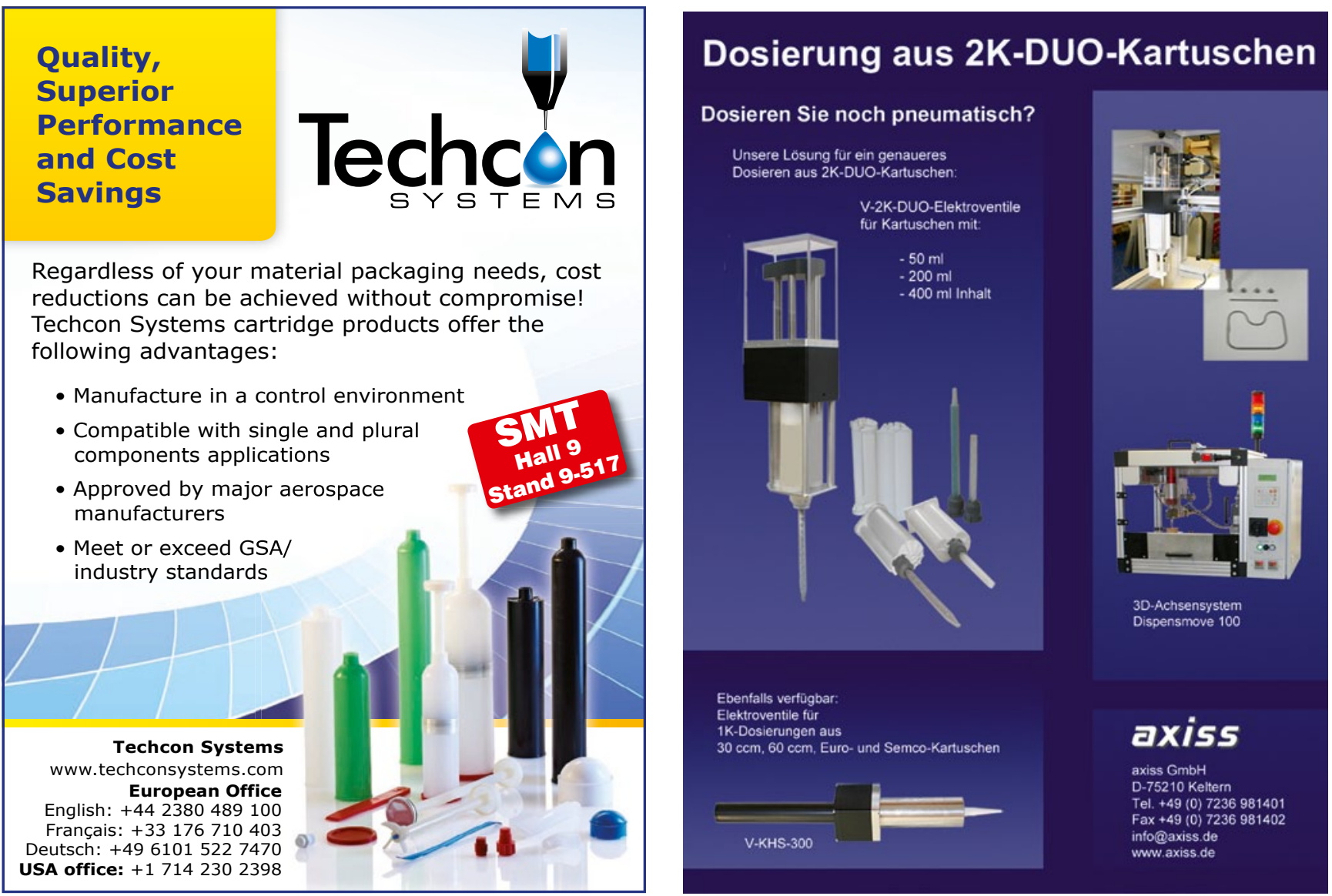